\title{
Pintura y pensamiento en Ramón Gaya
}

\section{Painting and Thought in Ramon Gaya}

\author{
Jacobo MuÑOZ VeIGA \\ Universidad Complutense de Madrid \\ escrituraeimagen@filos.ucm.es
}

Recibido: 23 de noviembre de 2010

Aceptado: 24 de noviembre de 2010

\section{Resumen}

La obra de Gaya, silenciada durante los largos años de la dictadura, está vinculada a la ciudad de Valencia. Allí, a instancias del autor de este artículo, el pintor murciano publica en 1961, en la revista La Caña Gris, un texto cuyo título definitivo fue "El fruto original". Valencia, convertida en capital intelectual y moral de la Europa antifascista, acogió a Ramón Gaya en 1937 y, tras su regreso del exilio, el pintor pasó allí muchas temporadas hasta hacer de ella, finalmente, su última residencia. Fue en esa ciudad donde un grupo de artistas e intelectuales al que pertenecía el pintor, fundó Hora de España, la gran revista republicana de ensayos, poesía y crítica, de la que Gaya, como Juan Gil-Albert y María Zambrano, fue alma indiscutible. En consonancia con el espíritu humanista de la ponencia colectiva presentada por el equipo de redacción de la revista en el II Congreso Internacional de Escritores, coordinado por la Alianza Internacional de Intelectuales Antifascistas, la obra de Gaya no acepta que lo real sea humillado y, lejos del realismo externo, su obra se distancia de la artificiosidad banal de los estilos del arte "artístico", abriéndose hacia un realismo metafísico, "más allá del arte".

Palabras clave: La República española, Valencia, intelectuales antifascistas, exilio, humanismo, arte, poesía, realismo metafísico.

\begin{abstract}
Gaya's work, silenced during the long years of the Spanish dictatorship, is linked to the city of Valencia. There, at the request of the author of this article, the
\end{abstract}


painter published in La Caña Gris, in1961, a text whose final title was "The original fruit." Valencia, converted into the intellectual and moral capital of the anti-fascist Europe, welcomed Ramón Gaya in 1937 and, after his return from exile, the painter spent many seasons there making it finally his last residence. It was in this town where Gaya with a group of artists and intellectuals, founded Hora de España, the great republican journal of essays, poetry and criticism, which Gaya, as Juan Gil- Albert and Maria Zambrano, was one of his key figures. In line with the humanist spirit of the collective presentation by the editorial board at the Second International Writers Congress, coordinated by the International Alliance of Antifascist Intellectuals, Gaya's work does not accept that the real is humiliated and, far from external realism, his work gets away from the trivial and affected styles of "artistic" art, while opening to a metaphysical realism, "beyond art.

Keywords: The Spanish Republic, Valencia, anti-fascist intellectuals, exile, humanism, art, poetry, metaphysical realism.

Tuve la fortuna de conocer personalmente a Ramón Gaya en Valencia, ciudad en la que vivió durante algún tiempo y en la que falleció, lo que no deja de tener un valor simbólico sobre el que no hará falta insistir. De eso, como de casi todo, hace ya mucho tiempo.

Tras largos años en México, Ramón Gaya volvió a Europa, concretamente a París, en 1952. Por aquellas fechas hizo un viaje a Venecia y otros lugares italianos con Juan Gil-Albert, residente casi invisible en Valencia desde su regreso del exilio en 1947, y con Concha de Albornoz, gran amiga de ambos. Tras un retorno breve a México, Gaya se instaló finalmente en Roma, lo que le permitió frecuentar a la irrepetible María Zambrano, prolongando así una relación que fue intensa en los años de la República y de la guerra. En marzo de 1960 volvió por vez primera a España. Expuso, presentado por Bergamín, en la Galería Mayer y publicó, por esas mismas fechas, uno de sus libros centrales, El sentimiento de la pintura. Seguidamente, hizo una escapada a Valencia.

Fue entonces cuando Juan Gil-Albert, que me había hablado mucho de Gaya en los años anteriores -los años de su absoluto exilio interior en Valencia tras su regreso, que no todos comprendieron-, organizó nuestro encuentro en su casa. Durante una larga -y para mí apasionante- tarde hablamos de la guerra; de Hora de España, la gran revista republicana de la que, como Juan Gil-Albert o María Zambrano, Gaya fue alma indiscutible; de su generación; de su exilio; de su pintura y de su pensamiento. De su estética, en una palabra. Conseguí incluso que accediera a publicar en La Caña Gris, revista de "poesía y ensayo" fundada por mí mismo y algunos otros estudiantes de letras valencianos, en el número doble $4 / 5$, correspon- 
diente al otoño de 1961, un trabajo cuyo título inicial -"El fruto original"- fue sustituido, a instancias de Juan Gil-Albert, por otro más llamativo -"El fruto prohibido"-. Con muy buen criterio, los editores de las Obras Completas de Gaya (Pretextos, 2010) lo han devuelto a la versión original. La Caña Gris vivió esta colaboración de Gaya como un gran honor, como la posibilidad de cooperar, todo lo modestamente que se quiera, al reconocimiento de una gran figura española que por los terribles azares de nuestra historia sólo conocían entonces (como en el caso de María Zambrano, o del mismo Cernuda) unos pocos en España. Algunos supervivientes... En realidad, la verdadera recuperación de las "grandes" -y no tan grandes- figuras de la "España peregrina" aún habría de esperar algunos años. Y no afectó en igual medida a todos...

Convendría recordar que en el caso de Gaya, o de los otros "grandes" que he citado, su pertenencia generacional se alzó muy pronto como factor perturbador. Incluso como "condición de imposibilidad" del natural despliegue de sus carreras y de sus obras, ferozmente silenciadas durante los largos años de la dictadura. Ramón Gaya fue un miembro prominente -emblemático- de la generación del 36, como el propio Cernuda, generalmente situado en la del 27. Yo preferiría hablar, en cualquier caso, de "constelación". A ella pertenecían, desde luego, todos los miembros del consejo de redacción ${ }^{1}$ de Hora de España, revista de ensayo, poesía y crítica, que se definía como publicación periódica, mensual, "al servicio de la causa popular". En aquella "guerra de España contra sí misma" por decirlo con Gaya.

La revista contó con la colaboración regular de Antonio Machado y con colaboraciones originales de autores como Dámaso Alonso, Julián Marías, Rafael Alberti, Emilio Prados, Luis Cernuda, León Felipe, José Bergamín, Concha Méndez, Miguel Hernández, Rosa Chacel... Se sucedieron como secretarios Sánchez Barbudo y Juan Gil-Albert. María Zambrano se incorporó pronto al consejo de redacción.

Las posiciones políticas concretas de quienes hicieron posible el milagro de Hora de España, que fue apareciendo con asombrosa puntualidad, no fueron homogéneas. Pero prácticamente todos ellos compartieron el "espíritu" de esa generación o constelación: en lo intelectual y moral (entendido como libertad de experimentar nuevas formas de vida), liberalismo; en lo económico, socialismo; en lo político, democracia; en lo estético, máxima autoexigencia en su oscilación entre el clasicismo y la vanguardia y, sobre todo, una fidelidad absoluta a la causa de la Segunda República. Algo por lo que todos pagaron un precio muy alto: la muerte, el exilio o la cárcel (Miguel Hernández).

1 El consejo de redacción estaba formado por M. Altolaguirre, Rafael Dieste, Antonio Sánchez Barbudo, Juan Gil-Albert y Ramón Gaya, autor de las viñetas de todos los números de la revista, desde el primero -Enero de 1937- al último, octubre de 1938. En total, 22 números. 
Con todo, aquella generación de sino tan trágico tuvo un talante más bien constructivo y esperanzado en lo que afecta a España, inseparable quizá del voluntarismo reformista de sus mejores representantes. Gaya, por ejemplo, colaboró activamente, al igual que Cernuda, María Zambrano, Rafael Dieste o García Lorca en las Misiones Pedagógicas de la República, haciendo, por ejemplo, copias de los cuadros más famosos del Prado para su exposición en el Museo itinerante del pueblo. El cartel de este Museo fue también suyo.

Cierto es que el propio Gaya hablaría y subrayaría la falta de continuidad del genio en España, de nuestra proverbial incapacidad para crear tradiciones, poniéndola en relación con esa condición dura, inhóspita, que presuntamente encontraríamos en todo lo español. Cierto es también que María Zambrano, particularmente acuciada, ya en el exilio, por la pregunta decisiva “¿Qué es España?” llegaría un día a escribir que "inteligencia" y "España" son "términos antitéticos" y que Cernuda la definiría como una "madrastra" habitada por seres de entraña dura. Y, con todo, el acento de esta constelación no era el del 98. Su mirada no quedó fija e inmóvil, como en el caso de los grandes del 98, en una España "agonizante" (Maragall), "sumida en el marasmo" (Unamuno), "tristísima" (Azorín), "cainita" (Machado), "país del rencor" (León Felipe), "mezquina" (Baroja) e "invertebrada" (Ortega). Los escritores, artistas y pensadores del 36, hijos de la Segunda República, estaban demasiado entregados al ideal regeneracionista y reformista, reformador y modernizador, al proyecto de futuro, en fin, que vinculamos con ella, como para quedar definitivamente abrasados por el pesimismo metafísico de sus antecesores. De lo contrario, no habrían luchado como lucharon. En el caso de Gaya, además, no se trataba sólo de su adhesión a los ideales de la Segunda República. Habría que leer con detenimiento su "Milagro español", ese conjunto de textos breves, de genuinas "iluminaciones" que dedicó en los años 50 del pasado siglo -en su etapa mexicana, por tanto- a Galdós, a Pastora Imperio, a Picasso, a Bergamín, a Don Quijote, entre otros, en los que Gaya hace justicia al tiránico instinto de lo esencial, a la natural intensidad y a la conciencia de la unidad suprema de arte y vida propias del mejor genio español, capaz incluso de convertir la locura en un camino privilegiado hacia una cordura superior, hecha de reciedumbre y sentido de la tierra. En las antípodas, pues, del gusto por el artificio tan característico del arte francés. $\mathrm{O}$, también, del italiano.

Documento crucial para comprender este espíritu es, sin duda, la ponencia colectiva presentada por los redactores de Hora de España, que jamás fue una revista "de propaganda" ni subordinó la lógica de la creación intelectual a los mandatos del comisario político de turno, o a exigencias ajenas a las de la veracidad y la calidad, en el II Congreso Internacional de Escritores, coordinado por la Alianza Internacional de Intelectuales Antifascistas, celebrado en Madrid y -sobre todo- en 
Valencia en Julio de 19372. En aquel momento estelar, Valencia fue la capital real de la República Española, como bien narró Juan Gil-Albert en su Memorabilia. Es más, fue, en realidad, la capital intelectual y moral de la Europa antifascista.

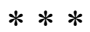

Pintura y pensamiento, plasticidad y crítica se dieron en principio cita en Gaya de un modo prácticamente "único", y no accidental. Porque esa unión fue -y es- tal por obra de lo que a ella subyace -en un sentido incluso metafísico-: una determinada estética, tan vivida como razonada y ejercida por su autor directamente como pintor o, a propósito de sus artistas más admirados: Juan Ramón Jiménez, como escritor y crítico, y Velázquez como pintor. Aunque: ¿autor o recipiendario de un don supremo, irreductible, de orden, digamos, "básico"...? Algo de esa estética quedó formulado ya en sus colaboraciones en Hora de España. En su debate, por ejemplo, con el cartelista valenciano Josep Renau. O en una carta a Juan Gil-Albert, en respuesta a otra de este a él mismo ("Cartas bajo un mismo techo"3). Y, finalmente, en un texto no menos revelador ("Un busto de "Pasionaria", por Victorio Macho"4).

\footnotetext{
2 "No negamos el arte de propaganda, pero nos parece, por si sólo, insuficiente. En tanto que la propaganda vale para propagar algo que nos importa, nos importa la propaganda. En tanto que es camino para llegar al fin que ambicionamos, nos importa el camino, pero como camino. Sin olvidar en ningún momento que el fin no es, ni puede ser, el camino que conduce a él. Lo demás, todo cuanto sea defender la propaganda como un valor absoluto de creación, nos parece tan demagógico y tan falto de sentido como pudiera ser, por ejemplo defender el arte por el arte". Así, pues, ni esteticismo, ni propagandismo "puro". Humanismo, esto es "aquello que intenta comprender al hombre, a todos los hombres, a fondo. Entendemos el humanismo como el intento de restituir al hombre la conciencia de su valor, de trabajar para limpiar la civilización moderna de la barbarie capitalista, que en la práctica -dice Unamuno en su ensayo La dignidad humana- ha trazado una escala de gradación para estimar el trabajo humano y se ha fijado en ella un punto cual cero de la escala, un punto terrible en el que empieza la congelación del hombre, en el que el despreciado o el adscrito va lentamente deshumanizándose, muriendo poco a poco, en larga agonía de hambre corporal y espiritual, entretejida".

Esta ponencia colectiva, firmada por A. Sánchez Barbudo, Ángel Gaos, Antonio Aparicio, A. Serrano Plaja, Arturo Souto, Emilio Prados, Eduardo Vicente, Juan Gil-Albert, J. Herrera Petere, Lorenzo Varela, Miguel Hernández, Miguel Prieto y Ramón Gaya, fue leída por Arturo Serrano Plaja. Hora de España la publicó, junto con las demás ponencias, de Machado, Andersen Nexo, Julien Benda, Fernando de los Ríos, Anna Seghers, José Bergamín, Ilya Ehrenburg, Tristan Tzara, Stephen Spender, Juan Marinello, entre otros, y los dibujos que Gaya hizo de las cabezas de algunos congresistas, en el $\mathrm{n}^{\circ}$ VIII (1937). El grafismo corrió a cargo de Manuel Altolaguirre. Por su parte, Gaya hizo también retratos inolvidables de sus compañeros de redacción y de lucha, entre ellos de Gil-Albert y Cernuda.

${ }^{3}$ Hora de España, II, 29 y 30.

4 Ibid., 462.
} 
Sugeriré, para terminar, que Ramón Gaya es el último vástago -un vástago herético y sumamente idiosincrásico- de la gran Tradición del realismo español, caracterizable según María Zambrano, por ejemplo, por recurso a rasgos como el predominio de lo espontáneo, de lo inmediato, el asentimiento al mundo, la aceptación amorosa de la realidad, a la que el español gusta de atenerse, el favorecimiento de un saber popular, asistemático, y a la vez profundo y fuente de cultura. Y, finalmente, la preferencia por el conocimiento poético, que traduce toda una actitud ante la realidad, todo un modo-de-estar-en-el-mundo que busca la fusión con él, que no permite que nada de lo real sea humillado, ni menos soporta el abandono del principio de concreción o la ruptura de la unidad de lo humano en la naturaleza y con lo que está "más allá de él".

No es este, ciertamente, un realismo "externo". Es, y de modo eminente, un realismo metafísico, esencial, trascendente, hecho carne en la más pura transparencia. Esto es: "alma desnuda". Por eso para Gaya el arte es lo contrario de artificiosidad, de entrega banal a los estilos, de arte "artístico". Es algo que, como en Velázquez, queda, en su suprema realidad viva, "más allá del arte"... Algo que ni siquiera habita en su materialidad concreta o en su textura formal, sino en su condición de substancia verdadera, secreta, de la realidad, capaz pues de autotrascenderse. Y es este dato incandescente lo que explica -siempre según Gaya- que toda plasticidad desaparezca en Las Meninas, que fueran precisamente las palabras lo que Juan de la Cruz borró de sus Canciones o que en Mozart si algo se revela como ausente es el ruido del sonido. O, en fin, que los poemas de Animal de fondo, de Juan Ramón Jiménez, no parezcan estar escritos. Así pues: realidad verdadera, viva, trascendencia, transparencia, alma desnuda, creación absoluta, carne de la realidad, substancia interior, invisible, que es capaz de ofrecerse a los ojos del pintor verdadero, nato.

Sobre todo, realidad que es vida, vida que es realidad. Vida, el único trascendental verdadero, del que la propia muerte es un momento esencial. 